\title{
O espaço da tradução em âmbito institucional: considerações sobre os contextos acadêmico e governamental sob a ótica da virada do poder
}

DOI: http://dx.doi.org/10.21165/el.v50i1.3074

\section{Rafaela Araújo Jordão Rigaud Peixoto'}

\section{Resumo}

Neste artigo, será realizada uma breve retrospectiva sobre o desenvolvimento da área de Estudos da Tradução, a fim de compreender de que forma as diversas influências históricas definiram seu atual estado-da-arte e o processo de institucionalização da disciplina. Com base em Snell-Hornby (2006) e Blume e Peterle (2013), serão analisados nove perfis de seleções públicas de concursos e credenciamentos, a fim de tecer considerações sobre o efetivo espaço da tradução (e do tradutor) no âmbito institucional. Como resultado, observou-se que, embora um passo importante tenha sido dado no sentido de oferecer espaço institucional para a tradução e, principalmente, para o tradutor, essa mudança de paradigma, como denomina Lambert (2013), ainda ocorre de forma bastante paulatina, sem necessariamente conferir-lhes a devida expressividade em procedimentos estabelecidos dentro dessas instituições.

Palavras-chave: estudos da tradução; tradução institucional; tradução especializada.

1 Departamento de Controle do Espaço Aéreo (DECEA), Rio de Janeiro, Rio de Janeiro, Brasil; rafaela.peixoto@gmail.com; http://orcid.org/0000-0002-3504-8405 


\title{
The space of translation within the institutional realm: considerations on academic and governmental contexts from the perspective of the power turn
}

\begin{abstract}
In this paper, a brief overview of developments in the field of Translation Studies will be presented, to understand how several historical influences defined its current state-of-theart and institutionalization process. Based on Snell-Hornby (2006), and Blume and Peterle (2013), nine profiles of competitive examinations and selection processes will be analyzed, in order to draw considerations on the actual space of translation (and translators) within the institutional realm. As a result, it was observed that despite the fact an important step has been taken towards providing institutional space to translation and, mainly, to the translator, this paradigm change, as mentioned by Lambert (2013), still occurs gradually, without necessarily stressing the significance of translation in procedures established within these institutions.
\end{abstract}

Keywords: translation studies; institutional translation; specialized translation.

\section{Introdução}

Neste artigo, será realizada uma breve retrospectiva sobre o desenvolvimento da área de Estudos da Tradução, a fim de compreender de que forma as diversas influências históricas definiram seu atual estado-da-arte e o processo de institucionalização da disciplina. Nesse contexto, com base nos pressupostos de Snell-Hornby (2006) e de Blume e Peterle (2013), serão analisados perfis de seleções públicas de concursos e credenciamentos, a fim de tecer considerações sobre o efetivo espaço da tradução (e do tradutor) no âmbito institucional, mais especificamente em entidades governamentais, sob a ótica da virada do poder.

É fato que, por ser tradicionalmente permeada de profissionais com formações diversas, há uma tendência a posicionar a profissão de tradutor apenas como uma atividade auxiliar, em que o conhecimento especializado se faz mais importante do que o conhecimento linguístico e o fazer tradutório. Nesse âmbito, são verificadas poucas oportunidades de trabalho efetivo em instituições governamentais, uma vez que profissionais de outras áreas, sobretudo técnicas, geralmente assumem o trabalho de tradução. Nas últimas duas décadas, é sabido que houve menos de dez concursos e alguns credenciamentos para a área de tradução, para candidatos com nível médio ou nível superior. Dessa forma, a fim de analisar a percepção do perfil do tradutor e a sua inserção em espaços institucionais, os editais de alguns desses concursos e credenciamentos foram contrastados, marcando algumas distinções de cargos, números de vagas, pré-requisitos, conhecimentos necessários para a seleção e atribuições do profissional. Com base 
nessas análises, pretendeu-se verificar, sob a ótica da virada do poder, a amplitude das influências relativas ao espaço institucional da tradução (e do tradutor).

\section{Metodologia}

A metodologia deste trabalho consistiu na apreciação de nove editais de seleções públicas de concursos e credenciamentos, a fim de analisar qual o efetivo espaço da tradução (e do tradutor) no âmbito institucional, tendo em vista suas influências, sob a ótica da virada do poder (SNELL-HORNBY, 2006; BLUME; PETERLE, 2013). Para tanto, foram contrastados nove perfis de cargos de concursos e de funções credenciadas, conforme descrito em editais para provimento de vagas para (A1) uma universidade federal, (A2) uma instituição do Poder Legislativo, (A3) um órgão do Poder Executivo, (A4) uma fundação pública federal, (A5) uma Junta Comercial Estadual e (A6) uma empresa pública do Poder Executivo; e para (B1) uma instituição do Poder Legislativo, (B2) uma autarquia federal vinculada ao Poder Executivo e (B3) um órgão do Poder Executivo².

\section{Breve retrospectiva do desenvolvimento dos estudos da tradução}

Os estudos da tradução percorreram caminhos erráticos ao longo dos anos, defendendo, em alguns momentos, inclusive teorias já propostas anteriormente. Vermeer (1992 apud SNELL-HORNBY, 2006) propõe que o progresso do campo dos Estudos da Tradução deu-se de quatro formas: (1) mudança paradigmática; (2) mudança espiral peripatética; (3) círculo perfeito e (4) espiral zigue-zague. Na primeira, a mudança ocorreu com base em cisões completas; na seguinte, houve meandros e discussões que, ao final, levaram a uma evolução; na terceira, as discussões retomaram um mesmo ponto já estabelecido anteriormente, sem evolução propriamente dita; e, na última, houve debates intensos, mas, ao final, conseguiu-se avançar um pouco teoricamente.

Nesse sentido, ao mesmo tempo em que a retomada de teorias já estudadas anteriormente causou certa estagnação no desenvolvimento dos estudos, elas também serviram para amadurecer perspectivas. Goethe, por exemplo, teve suas percepções reanalisadas e refutadas ao longo dos anos, mas, atualmente, sua ideia de que a tradução deveria localizar-se em um meio-termo, em busca de uma identidade própria, tem sido considerada um ponto de muita perspicácia acadêmica. Pode-se dizer que os estudos contemporâneos estão majoritariamente direcionados para essa perspectiva.

É fato que naquela época, em que ainda não havia uma base sólida para os estudos da tradução, era assentada a dicotomia entre palavra e sentido, originada nos estudos de Horácio e Cícero. E, a partir daí, havia uma oposição entre uma tradução meramente mecânica e uma tradução "genuína", propriamente dita, que explorava a criatividade.

2 A fim de preservar a face das instituições cujos editais foram analisados neste artigo, optou-se por mencionar apenas o perfil organizacional dessas instituições. 
Schleiermacher (1993) teceu considerações frutíferas sobre a distinção entre tradução literária e tradução científica. A equiparação de elementos da língua a signos matemáticos pode ser considerada uma percepção pioneira de conceitos futuros da área da linguística estruturalista, da terminologia e da tradução automática. Uma das maiores contribuições de Schleiermacher, com base nas máximas apresentadas por Goethe e retomada por outros autores no futuro, é a discussão sobre a necessidade de o leitor ir ao encontro do autor ou de o autor ir ao encontro do leitor. Schleiermacher, no entanto, concluiu que os dois caminhos são completamente separados e que, de fato, o autor e o leitor nunca se encontrariam (Cf. LEFEVERE, 1977 apud SNELL-HORNBY, 2006). Venuti, por seu turno, defende uma perspectiva de domesticação, que parece tender à normalização e ser de elaboração "frágil", na medida em que é muito mais confortável apenas reescrever o texto sem ter um cuidado específico em manter características do texto-fonte, que podem ser mais difíceis de serem transpostas e/ou ressignificadas. No esteio dessa discussão, a tradução não precisa "lutar contra o sistema", mas, em vez disso, "unir-se a ele", com o intuito de agregar elementos que sejam enriquecedores para o texto da tradução, sem anular completamente a ideia do original.

$\mathrm{Na}$ sequência desse processo de desenvolvimento (não propriamente evolução cronológica) dos estudos da tradução, surgiram, após a Segunda Guerra Mundial, quando a tradução não-literária passou a ser mais valorizada, precursores imediatos que possuíam um background multicultural e raízes intelectuais, dentre os quais se destacou a Escola de Praga. Roman Jakobson, um de seus fundadores e também integrante da Escola do Formalismo Russo, criou, juntamente com Tynjanov, o conceito de "sistema de sistemas", passando a tratar a língua como um sistema semiótico. Outro pesquisador da Escola de Praga, Levy, focalizou a tradução literária e idealizou um modelo de tradução que preconizava a compreensão, a interpretação e a transferência de sentido. Para ele, fidelidade e estilo artístico não eram autoexcludentes (SNELL-HORNBY, 2006).

É relevante trazer à baila que, em um cenário pós-guerra, a internacionalização do inglês fortaleceu as bases para uma perspectiva sobretudo funcionalista, em que processos hermenêuticos, defendidos por Paepcke, eram mais valorizados e o conceito de equivalência passou a ser questionado. Para ele, não era possível criar uma fórmula, uma espécie de checklist, como havia sido feito muitas vezes anteriormente, sobretudo em uma visão aristotélica de definição, por exemplo (Cf. PEIXOTO, 2020). A tradução deveria sobretudo abarcar aspectos culturais e linguísticos em toda a sua diversidade.

A ideia de um movimento hermenêutico, conforme teorizado por Steiner, defende que o entendimento e a ressignificação do texto original em uma tradução subentendem uma reescrita. Conforme explicitado por Snell-Hornby (2006), as etapas desse movimento hermenêutico compreenderiam: initiative trust, aggression (or penetration), incorporation (embodiment) e restitution. Nessas etapas, haveria, respectivamente, uma percepção neutra do outro; uma incursão com vistas a extrair o que fosse interpretado como 
relevante; o realocamento desse elemento que tivesse sido apropriado e o movimento final de ressignificação, em que o tradutor buscaria "equilibrar os sentidos" (Ibidem, p. 31). Haveria, portanto, uma desconstrução do significado original, para ser ressignificado conforme o julgado mais adequado pelo tradutor (Cf. SNELL-HORNBY, 2006).

Inserido nesse background, e em meio a um movimento de tentativa de delimitação da área, Holmes idealizou um modelo para a área de atividades de tradução, que foi esquematizado por Toury e propagado por Snell-Hornby em seu livro Translation Studies: an integrated approach (Cf. LAMBERT, 2010). Holmes optou por dar o nome de Estudos da Tradução à nova área, pois abarcaria considerações de estudos terminológicos e lexicográficos comparativos (ou contrastivos), linguística comparativa ou contrastiva e teoria da tradução. (Cf. HOLMES, 2000 [1976]). Denominar a nova área Estudos da Tradução foi, na verdade, um dos insights mais brilhantes do pesquisador, haja vista ter possibilitado uma abordagem mais plural, sem foco na teoria ou na prática apenas tensão essa que, como relata Munday (2012 [2001]), acabava impondo óbices a alguns direcionamentos de estudo, considerados inicialmente pouco relevantes para abordagens teóricas, como no caso da tradução especializada.

Além disso, a perspicácia de Holmes de analisar uma abordagem pura descritiva sob a ótica de processo, produto ou função também possibilitou agrupar teorias que teriam sido consideradas bastante divergentes no que tange aos estudos da tradução. Snell-Hornby (1991 apud SHUTTLEWORTH; COWIE, 1997) ampliou o debate acerca das classificações importantes do campo de Estudos da Tradução, e destacou ser imprescindível abarcar desde a tradução literária até a tradução especializada, também englobando o campo da interpretação, geralmente negligenciado.

Atualmente o mapa proposto por Holmes é bastante questionado, sob a alegação de que os sentidos não poderiam ser totalmente elucidados somente com base em um produto, seja texto-fonte ou texto-alvo. Seria necessário considerar aspectos subjetivos, mediante análise do tradutor, viés que não é representado no "modelo" do autor. Arrojo (1998, on-line) afırma que ele "parece repetir a grande maioria de seus predecessores e contemporâneos em sua expectativa de que se pudesse, de alguma forma, organizar e unificar o que se pensa e prescreve em relação à tradução.". Tal afirmação parece ser um pouco contundente, dado que o fato de delimitar um determinado escopo-base de uma análise não impede a consideração de outras influências. O mapa de Holmes parece não ter tido um intuito prescritivo, mas, ao contrário, tenciona promover uma apreciação mais complexa do texto. Como o próprio Holmes (2000 [1976]) explica, a escolha do termo "estudos" para denominar a área foi uma tentativa de não conferir um status muito rígido para a classificação idealizada.

Outros autores que criticam o mapa de Holmes são Pym (1998) e Toury (apud PYM, 1998). O primeiro autor faz a ressalva de que o mapa não assegura o devido espaço ao tradutor, 
embora acredite que uma provável modificação do referido mapa poderia significar um enfraquecimento da área; Toury, por sua vez, afirma que o mapa buscaria promover uma "evolução controlada" dos Estudos da Tradução.

Uma alternativa seria não focalizar a delimitação da área de estudos da tradução, mas, sim, as possibilidades e reações possíveis dentro do campo, particularmente no concernente à atuação do tradutor. Nesse sentido, a ideia não seria prescrever, mas descrever e problematizar. A "fragmentação" não é negativa, mas, ao contrário, dá-nos a oportunidade de utilizar subsídios de outras áreas para enxergarmos mais além. Como pontuado por Snell-Hornby (2006), em função de sua perspectiva de considerar teoria e prática como igualmente importantes, sem defender um estudo puramente embasado em elementos canônicos, Holmes (2012 [2001]) aproxima-se da abordagem desconstrutivista de tradução.

Primeira escola de tradução do Brasil, a Desconstrução foi sobretudo introduzida por Rosemary Arrojo e Paul Ottoni, ambos da UNICAMP à época. Essa escola tornou-se tão influente e profícua, segundo Milton (2015), que alguns integrantes da comunidade científica estrangeira chegavam a reconhecê-la como único segmento de pesquisa dos Estudos da Tradução no Brasil.

No entanto, Britto (2001) acredita que a desconstrução de todos os paradigmas que vigoram acerca da tradução, conforme discutido por Arrojo no artigo "As questões teóricas da tradução e a desconstrução do logocentrismo: algumas reflexões" ${ }^{3}$, acabaria por excluir parâmetros para a atividade tradutória. Para Britto, o mérito da desconstrução reside em atentar para a necessidade de relativizar conceitos e, dessa forma, não seria salutar adotar essa perspectiva como uma total desconsideração dos antigos ideais logocêntricos. Pym (1998) corrobora essa perspectiva ao defender que estudos anteriores são tão importantes quanto possíveis novas teorias e, por isso, as perspectivas teóricas não podem ser encaradas de maneira estanque. O trabalho colaborativo também permitiria uma visão mais ampla sobre o objeto de pesquisa, uma vez que cada pesquisador teria uma dada área de especialidade mais desenvolvida: haveria análise de dados da prática tradutória, em associação com a teoria.

$\mathrm{Na}$ sequência desse desenvolvimento, a tradução continuou a refinar seus desdobramentos na década de 80. Por meio de sua narrativa conceitual (e disciplinar), que consiste em "histórias e explicações que estudiosos em qualquer campo elaboram

3 Britto elenca os seguintes pressupostos: "(1) é possível haver uma tradução 'literal', equivalente ao 'original', sem interferência do tradutor; (2) pode-se considerar um texto "original" como objeto estável, cujo significado identifica-se com a intenção consciente do autor, sendo irrelevantes a contribuição do leitor e seu contexto sociocultural e histórico; (3) o significado é um objeto distinto do estilo do texto em que ele aparece." (BRITTO, 2001, p. 42-43). 
para si próprios e para outros sobre seu objeto de investigação" (VASCONCELLOS, 2013, p. 34 apud BAKER, 2006, p. 166, grifos do autor). Milton (2015) destaca que a tradução literária obteve bastante atenção nesse momento, sobretudo em função de atividades fora da universidade. Haroldo de Campos, um dos poetas que mais contribuiu para esse cenário, cunhou o termo transcriação e, a partir dessa perspectiva, propôs foco na forma poética do texto, i.e. configuração fonosemântica, suplantando a dicotomia forma vs. conteúdo. A transcriação, ou recriação do texto, faria uso da criatividade do tradutor para encontrar soluções no âmbito de possibilidades semióticas de um poema, por exemplo.

Outro desdobramento foi em relação à perspectiva pragmática (Cf. SNELL-HORNBY, 2006), impulsionada sobretudo pela reclassificação de Coseriu para a dicotomia langue vs. parole: repensar o que poderia ou não ser considerado normativo seria o ponto central para idealizar uma teoria da linguagem. Consoante essa perspectiva, foi possível se chegar a uma consideração funcionalista, a qual, por fim, geraria um sem número de discussões acerca das possibilidades pragmáticas da língua.

Embora haja diferentes meandros das linhas de pensamento nas pesquisas sobre Estudos da Tradução (Cf. VERMEER, 1992 apud SNELL-HORNBY, 2006), não se pode obscurecer o fato de que posturas funcionalistas e formalistas, em um dizer mais "genérico", são interdependentes. É bastante temerário pensar em sentido ou efeito do texto sem considerar itens formais, embora estes não sejam sempre determinantes. Os estudos pragmáticos de fato elevaram consideravelmente as discussões linguísticas a um patamar nunca dantes visto e, no esteio dessa perspectiva, os Estudos da Tradução, mais do que qualquer outra área, foram bastante beneficiados com esse salto qualitativo.

Ao partir do pressuposto de que a tradução sempre reflete o contexto sócio-histórico, a virada cultural veio desconstruir a perspectiva formalista estanque, por considerar que critérios estéticos também são bastante subjetivos e volúveis. Esseé, em dúvida, o principal legado dessa reviravolta teórica, que também promoveu uma expansão vertiginosa dos escopos de pesquisa, como explica Bassnett $(2014$, p. 10) ao afirmar que "os estudos da tradução se desenvolveram em todas as direções possíveis desde 1980". Nessa esteira, foram lançadas as sementes para discussões acerca da institucionalização da disciplina, com a efetiva integração de espaços acadêmico e governamental.

\section{Institucionalização da tradução: integração de espaços acadêmicos e governamentais}

Estudos sobre a questão institucional vêm ganhando mais espaço (Cf. KOSKINEN, 2001; KANG, 2020), particularmente a partir de 2014, com o início da série de edições bianuais da International Conference on Economic, Business, Financial and Institutional Translation (ICEBFIT), em que passaram a ser mais amplamente discutidas instâncias de tradução em âmbito organizacional, e como a agência do tradutor pode influenciar ou modular o processo e o produto final dessas traduções institucionais. 
No entanto, a questão da institucionalização do campo da tradução, inicialmente no contexto acadêmico, vem sendo debatida desde a criação da disciplina Estudos da Tradução. Nesse processo, possíveis definições são mormente sujeitas a influências políticas (LAMBERT, 2013), e esforços engendrados em dadas épocas foram impactados por correntes contrárias que conferiam uma classificação sobretudo prática, não teórica, a essa disciplina.

Nesse contexto, o estabelecimento da disciplina inicialmente envolvia debates sobre distinções entre estudos linguísticos e literários: a tradução não era sequer considerada sob um viés acadêmico, haja vista não haver, à época, uma concepção canônica sobre tradução. A própria universidade ainda parecia indecisa sobre o objeto de estudo da tradução: haveria um foco na formação profissional do tradutor ou na tradição de pesquisa da área?

Em um cenário pós-segunda-guerra, a institucionalização da disciplina ocorreu como uma mera prestação de serviço e, dessa forma, houve ênfase em programas de formação de tradutores, em detrimento de estabelecimento de currículos acadêmicos. E, embora algumas instituições governamentais, como as Nações Unidas, e privadas, como a empresa IBM, tenham contribuído bastante para a sedimentação da atividade profissional de tradução e interpretação especializadas, a área apenas adquiriu status expressivo em poucas situações, como no caso do período pós-Apartheid da África do Sul, momento crítico em que a interpretação se tornou uma questão de justiça social. (LAMBERT, 2013).

Inicialmente, a não-institucionalização acadêmica deveu-se à natureza interdisciplinar da área de estudos da tradução, que perpetuou a fragmentação do campo. Uma abordagem empírica como ponto de equilíbrio de discussões teóricas, conforme defendido por Lefevere e Toury, na busca de revitalizar o campo, colocou a Bélgica na vanguarda das discussões, posição sobretudo possibilitada pela tradição multicultural e interlinguística do país. Nessa esteira, a própria União Europeia teria passado a privilegiar a pesquisa aplicada em detrimento da pesquisa puramente teórica. Além disso, a disseminação de recursos digitais, com o advento da internet, gerou uma necessidade de reformulação e adaptação de objetivos da disciplina, para atender a novas situações e ambientes, além de ter ocasionado a diminuição da influência das universidades.

O grupo de Leuven, na Bélgica, formado por pesquisadores de várias origens, em busca de um modelo que se opusesse ao panorama até então restrito da tradução, que ora privilegiava uma abordagem excessivamente estruturalista, ora focalizava apenas avaliações abstratas, passou a defender o estudo sistemático em universidades e o aperfeiçoamento do processo de formação de tradutores profissionais (BASSNETT, 2014). 
Nesse contexto, é possível afirmar, como defende Lambert (2013), que o cerne da discussão acerca da institucionalização da disciplina seria a incorporação dos estudos da tradução ao âmbito acadêmico. Assim, seria necessário mais apoio de parcerias internacionais, que vislumbrassem o campo além do conceito de normas culturais, em que há uma busca, irreal, por alinhamento a comunidades nacionais.

Para tanto, Lambert (2013) esclarece que a institucionalização decorre de um processo de mudança histórica e mudança de paradigmas de poder em uma sociedade organizada. Certas atividades culturais que ocorrem de forma individual, informal e desregulada vêm a institucionalizar-se posteriormente e, nesse momento, tendem a tornar-se conservadoras, canônicas.

Milton (2015), assim como Vasconcellos (2013), cita a influência de forças centrípetas e centrífugas no estabelecimento da disciplina. O movimento centrípeto tenderia a privilegiar formas canônicas de estudar a tradução, e o movimento centrífugo tenderia a vascularizar os estudos, de maneira a estabelecer interseções, embora isso signifique uma tendência à fragmentação. Sobre isso, Vasconcellos (2013) afirma que o movimento centrípeto representa o que éramos, enquanto o movimento centrífugo representa o que somos hoje e o que queremos ser amanhã, mediante a incorporação de novas capacidades eletrônicas de produzir e disseminar conhecimento.

O desafio, defende Lambert (2013), seria tentar articular o cenário globalizado, de maneira a incluir diversas comunidades de produção de comunicação, tais como, internet, mídia impressa, rede de televisão, mercado editorial, dentre outros. Isto, pois, a institucionalização deve utilizar, da melhor forma, abordagens funcionalistas, para atender a itens culturais particulares. Além disso, ainda de acordo com Lambert (2013), é fato que a implementação da institucionalização do campo de estudos da tradução depende de motivações industriais, isto é, financeiras, que levam à propagação de disciplinas de foco teórico aplicado. A área de Humanidades, por si só, nesse cenário, é considerada de pouco apelo, com escopo político-econômico mais restrito.

No esteio dessa discussão, Arrojo (1998) parece acreditar que a busca de formalização para a área seria, em última instância, uma tentativa de tentar conferir maior credibilidade ao campo, tradicionalmente permeado por profissionais sem formação específica em Letras. Em vista desse hibridismo, o panorama de "desorganização" e a consequente "falta de profissionalização" seria responsável por fazer com que a área não fosse respeitada ou sequer lembrada, como é o caso de enciclopédias reconhecidas que não mencionam o verbete "Tradução" ou o fazem de maneira muito reduzida (THEODOR, 1983 apud ARROJO, 1998). A solução de cada vez mais expandir a área, o que de certa forma traria o risco de excessiva fragmentação, ainda parece ser a solução mais estratégica, com o intuito de manter a "integridade" desse campo de estudos - por mais paradoxal que isso possa parecer. 
Ainda convergente com esse esforço, deve haver um empoderamento do profissional tradutor, de maneira a situá-lo em uma sociedade intercultural, com necessidades contemporâneas cada vez mais multifacetadas, tal como defende Pym (1998). A desconsideração do tradutor como vetor importante nesse processo de valorização da área, e de consequente institucionalização da disciplina, é evidenciada no próprio mapa fundador da área de Estudos da Tradução, elaborado por Holmes, no qual não houve destaque para o tradutor. Pym, no capítulo supracitado, salienta que o mapa proposto também teria uma função excessivamente normativa, de instituição de poder, haja vista a nominalização ser uma forma de controlar. Nessa esteira, a própria hierarquização do mapa, top-down, indicaria uma verticalização dos elementos a serem estudados, diferentemente de um outro mapa proposto por Humphrey, de orientação horizontal.

Em se considerando esses aspectos do processo de desenvolvimento e de institucionalização da área de Estudos da Tradução, é importante compreender as influências da virada do poder no sentido de elevar a tradução a um novo patamar de empoderamento institucional.

\section{Virada do poder: um novo patamar de empoderamento institucional}

Ao tomar por base o contexto explicitado nos tópicos anteriores, é possível afirmar que a expressão de conceitos de poder passa a ser determinante para a maneira como as traduções são realizadas. Nesse âmbito, desde 1990 têm sido discutidas questões relativas à interrelação entre tradução e poder, mediante a análise da influência do papel do poder em sociedade, particularmente no que diz respeito à produção de cultura. Tal discussão se deu em decorrência de desdobramentos da virada cultural (GENTZLER; TYMOCZKO, 2002). Essa postura, ao fim e ao cabo, está imbuída de uma projeção de senso de poder (ou empoderamento), sobretudo originada do arcabouço cultural do tradutor.

As práticas textuais, nessa esteira, refletem as estruturas de poder dentro de um contexto cultural mais amplo, no qual a tradução cria uma imagem para aqueles que não têm acesso ao original (ÁLVAREZ; VIDAL, 1996); e, dessa forma, a subdivisão virada do poder focaliza sobretudo a habilidade de atuar sobre estruturas de comando, com o propósito de resistir a propósitos de colonização ou exploração (Cf. GENTZLER; TYMOCZKO, 2002). No entanto, vale salientar que a atuação do tradutor também não pode ser deliberada; deve haver um limite, sob pena de a tradução ser muito caricata e não representar minimamente o original.

O ponto mais alto da virada do poder é exatamente a questão de que a tradução pode ser manipulada com o propósito de deixar transparecer uma determinada ideologia, que, em última instância, teria a pretensão de também influenciar o leitor e construir o tipo de cultura desejada. Tais estruturas de poder podem ocorrer de maneira formal ou informal, 
implícita ou explicitamente. Como defendem Gentzler e Tymoczko (2002, p. xvi), nesse contexto, merece destaque exatamente a questão da agência, particularmente em relação ao profissional tradutor, que pode vir a privilegiar uma determinada postura discursiva acerca de um dado texto, embora o próprio texto ainda permita outras interpretações.

Por este motivo, Blume e Peterle (2013) afirmam que seria mais importante focalizar o processo de produção de uma tradução, a fim de analisar as variáveis, especialmente as relações de poder, que contribuem ou influenciam a escrita do tradutor. Além disso, também parece ser importante, mais especificamente, analisar o espaço do próprio tradutor, não apenas o processo, a fim de ter um ponto de referência para a análise de suas ações em relação ao texto traduzido.

A tradução evidencia, portanto, várias facetas de poder, na medida em que atua como vetor de transformação e mudança. Sobre essa questão, Gentzler (apud GENTZLER; TYMOCZKO, 2002, p. xxxviii, tradução nossa4) posiciona-se, afirmando que:

O tradutor nunca é neutro no processo de tradução, mas sempre está envolvido no processo de produção textual [...] a tradução não é um lugar neutro de intercâmbio livre e aberto, mas um lugar contestado por instituições e indivíduos poderosos, que envolve o tradutor em diversos discursos de gênero, étnicos e de classe. [...] o processo de tradução pressupõe gestão e modulação de informações que podem ser utilizadas para fins sociais de grande impacto [...] a tradução situase em instâncias de afırmação de poder militar e político, assim como domínio econômico e cultural.

No esteio das discussões até aqui empreendidas, as análises deste artigo em relação aos concursos e credenciamentos de tradutores será realizada em três etapas: quanto à descrição do cargo e ao número de vagas (primeira etapa); como comparação de prérequisitos e atribuições para as seleções de concursos e credenciamento de tradutores (segunda etapa); e no referente aos conhecimentos necessários (terceira etapa).

Em relação à primeira etapa, os dados extraídos dos editais selecionados foram dispostos no Quadro 1 a seguir.

4 No original: "[...] the translator is never neutral in the translation process but is always already involved in the process of textual production [...] translation is not a neutral place of free and open exchange, but a site contested by powerful individuals and institutions, involving the translator in any number of gender, ethnic, and class discourses. [...] the process of translation is one of gathering and staging information that can be used for powerful social ends [...] translation figures in the assertion of political and military power, as well as cultural and economic dominance.". 
Quadro 1. Comparação de descrição do cargo e número de vagas para as seleções de concursos e credenciamentos de tradutores

\begin{tabular}{|c|c|c|}
\hline Edital & Descrição do cargo & Número de vagas \\
\hline A1 & Tradutor e Intérprete & 1 (ampla concorrência) \\
\hline A2 & Analista Legislativo - Tradução e Interpretação & $\begin{array}{l}1 \text { (ampla concorrência); } 1 \\
\text { (reservada) }\end{array}$ \\
\hline A3 & Tradutor e Intérprete & 3 (ampla concorrência) \\
\hline A4 & $\begin{array}{l}\text { Analista de Planejamento, Gestão e Infraestrutura } \\
\text { em Informações Geográficas e Estatísticas A I } \\
\text { (Letras Português/Inglês) }\end{array}$ & 4 (ampla concorrência) \\
\hline A5 & [função] Tradutor Público e Intérprete Comercial & $\begin{array}{l}\text { Todos os aprovados com no } \\
\text { mínimo } 7,0 \text {. }\end{array}$ \\
\hline A6 & $\begin{array}{l}\text { Analista Classe A - Gestão da informação: } \\
\text { (a) Edição espanhol e (b) Edição inglês }\end{array}$ & $\begin{array}{l}2 \text { (ampla concorrência, Centro } \\
\text { Oeste) + } 2 \text { (cadastro de reserva) }\end{array}$ \\
\hline B1 & $\begin{array}{l}\text { [função] Credenciado para tradução/versão dos } \\
\text { pares de idioma português-inglês, português- } \\
\text { espanhol, português-francês e português-alemão. }\end{array}$ & Todos os aprovados \\
\hline B2 & $\begin{array}{l}\text { [função] Tradutor em língua inglesa, francesa } \\
\text { ou espanhola para exames e avaliações da } \\
\text { educação básica }\end{array}$ & Todos os aprovados \\
\hline B3 & $\begin{array}{l}\text { [função] Prestador de serviço para tradução } \\
\text { juramentada de documentos comuns, jurídicos } \\
\text { e técnicos de diversos idiomas para a língua } \\
\text { portuguesa e vice-versa. }\end{array}$ & Todos os aprovados \\
\hline
\end{tabular}

Fonte: Adaptado dos respectivos editais dos concursos

Ao apreciar os dados do Quadro 1, observa-se variação da denominação do cargo - como Tradutor ou Analista -, com apresentação de descrição de atividades que evidenciam a devida complexidade da atuação do tradutor. No entanto, ainda não há um espaço institucional efetivamente mais resguardado para a função e o profissional, o que pode ser corroborado pelo número de vagas oferecidas em concursos (que possuem estabilidade) e credenciamentos (geralmente com vigência de dois anos): nos concursos, as vagas são mínimas, ao passo que nos credenciamentos (e, no caso de $A 5$, concurso com atribuição de função, para atender a público-alvo externo) as vagas não possuem limitação. Tal distinção, deve-se ressaltar, não tem necessariamente relação direta com a demanda do trabalho, haja vista algumas das referidas instituições governamentais certamente terem uma demanda de trabalho bastante superior ao que em tese faria supor o quantitativo 
de vagas. É bastante provável, como citado por Milton (2015), que as empresas apenas designem outros profissionais de seu quadro técnico para desempenharem a função de tradutor.

Para a segunda etapa de análises, o contraste entre pré-requisitos e atribuições é evidenciado, respectivamente, no Quadro 2 e no Quadro 3.

Quadro 2. Comparação de pré-requisitos para as seleções de concursos e credenciamentos de tradutores

\begin{tabular}{|c|l|}
\hline Edital & \multicolumn{1}{|c|}{ Pré-requisito } \\
\hline A1 & Graduação concluída em Letras - Português-Inglês \\
\hline A2 & Nível superior em Letras (reconhecida pelo MEC) \\
\hline A3 & Graduação em Letras com habilitação em Inglês \\
\hline A4 & Curso Superior completo em Letras (Português/Inglês) \\
\hline A5 & $\begin{array}{l}\text { Ser cidadão brasileiro nato ou naturalizado, não ser empresário falido não reabilitado, } \\
\text { ser residente e domiciliado por mais de um ano no Estado dx [suprimido] e não ter sido } \\
\text { anteriormente destituído do ofício de tradutor público e intérprete comercial. }\end{array}$ \\
\hline B1 & $\begin{array}{l}\text { Graduação (inglês ou espanhol), Mestrado em Tradução (inglês ou espanhol) e 6 } \\
\text { meses de experiência profissional na área da Gestão Informação. }\end{array}$ \\
\hline B3 & $\begin{array}{l}\text { Curriculum vitae do proponente, demonstrando experiência como tradutor no(s) } \\
\text { par(es) de língua(s) para o(s) qual(is) está solicitando credenciamento; e Atestado(s) } \\
\text { de capacidade técnica fornecido(s) por pessoa jurídica de direito público ou privado, } \\
\text { que comprove(m) a execução de serviço(s) de tradução e/ou versão declarado(s) no } \\
\text { currículo. }\end{array}$ \\
\hline B2 & $\begin{array}{l}\text { - Possuir graduação em curso de Bacharelado em Tradução ou Letras - Tradução } \\
\text { (Inglês, Francês ou Espanhol), reconhecido pelo MEC. } \\
\text { - Possuir experiência no exercício de atividade de docência ou pesquisa no ensino } \\
\text { básico ou superior, público ou privado.; e } \\
\text { - - Alcançar pontuação mínima de 4 Pontos nos requisitos Complementares mestrado/ } \\
\text { doutorado, experiência profissional, cursos de formação complementar, produção } \\
\text { científica). }\end{array}$ \\
\hline & $\begin{array}{l}\text { Termo de ou inscrição na Junta Comercial do Estado em que resida, } \\
\text { comado/público. }\end{array}$ \\
\hline
\end{tabular}

Fonte: Adaptado dos respectivos editais dos concursos 
Quadro 3. Comparação de atribuições para as seleções de concursos e credenciamentos de tradutores

\begin{tabular}{|c|c|}
\hline Edital & Atribuições \\
\hline A1 & $\begin{array}{l}\text { Examinar o texto final a ser traduzido; transpor o texto a outro idioma, consultando } \\
\text { dicionários e outras fontes de informação; fazer traduções literárias de língua } \\
\text { estrangeira, conservando o rigor idêntico dos mesmos e o estilo e sentimento } \\
\text { expressos; revisar o texto traduzido; preparar síntese de textos traduzidos; traduzir os } \\
\text { diálogos realizados entre pessoas que falam idiomas diferentes; efetuar a tradução } \\
\text { simultânea de discursos pronunciados em conferências internacionais, debates e } \\
\text { outras reuniões análogas; interpretar discussões e negociações entre pessoas que não } \\
\text { falam a mesma língua; pode especializar-se em um determinado campo da tradução e } \\
\text { interpretação a ser designado de acordo com sua especialidade. }\end{array}$ \\
\hline A2 & $\begin{array}{l}\text { Desenvolver atividades de tradução, interpretação e versão de documentos legislativos } \\
\text { e administrativos de interesse dx [suprimido] e executar outras tarefas correlatas. }\end{array}$ \\
\hline A3 & $\begin{array}{l}\text { Atividade de nível superior envolvendo planejamento, supervisão, coordenação, } \\
\text { controle e assessoramento referentes ao desenvolvimento de atividades de tradução, } \\
\text { interpretação e versão de documentos legislativos e administrativos de interesse de } \\
\text { defesa aérea e controle de tráfego aéreo. }\end{array}$ \\
\hline A4 & $\begin{array}{l}\text { Desenvolver trabalhos de revisão, tradução e versão de textos para uso em mídia } \\
\text { impressa, audiovisual e digital, incluindo Internet; e executar outras atividades } \\
\text { compatíveis com o cargo. }\end{array}$ \\
\hline A5 & $\begin{array}{l}\text { Profissionais autônomos habilitados por concurso público promovido pelas Juntas } \\
\text { Comerciais de cada Estado, cujas traduções possuem fé pública em todo território } \\
\text { nacional. }\end{array}$ \\
\hline A6 & $\begin{array}{l}\text { Profissional para gerenciar, coordenar, avaliar e participar de projetos e subprojetos } \\
\text { de suporte à pesquisa e desenvolvimento; administrar, analisar, executar, orientar e } \\
\text { assessorar e desenvolver estudos estratégicos em processos, projetos e subprojetos } \\
\text { nas áreas de laboratórios e campos experimentais, suprimento, manutenção e serviços, } \\
\text { gestão de pessoas, orçamento e finanças, gestão da informação, transferência de } \\
\text { tecnologia e comunicação empresarial, direito e auditoria e gestão estratégica. }\end{array}$ \\
\hline B1 & $\begin{array}{l}\text { Realização de tradução e versão, conforme sistema de rodízio, em regime normal, de } \\
\text { urgência ou de extrema urgência. }\end{array}$ \\
\hline B2 & $\begin{array}{l}\text { Trabalho, presencial ou a distância, de revisão técnico-pedagógica e linguística de itens } \\
\text { que comporão o Banco Nacional de Itens e os questionários utilizados nas avaliações, } \\
\text { exames e pré-testes. }\end{array}$ \\
\hline B3 & $\begin{array}{l}\text { Realização de tradução e versão juramentada de documentos comuns, jurídicos e } \\
\text { técnicos de diversos idiomas, conforme sistema de rodízio, em regime normal, de } \\
\text { urgência ou de extrema urgência. }\end{array}$ \\
\hline
\end{tabular}

Fonte: Adaptado dos respectivos editais dos concursos 
Com base nos dados aqui expostos, pode-se perceber que enquanto os concursos, mormente para provimento de cargo efetivo, priorizam um perfil acadêmico, os credenciamentos, por sua vez, enfatizam a experiência profissional. Neste último caso, insere-se inclusive o concurso A5, exceção do padrão de concursos, o que vem a corroborar essa observação assinalada. Na mesma esteira, B2 também é uma exceção ao mencionado padrão de credenciamentos, uma vez que exige eventual formação acadêmica de nível de pós-graduação para o provimento da função. No caso dos concursos, o nível de pós-graduação é, ainda, requisito obrigatório no caso de A6.

Em relação a essa comparação, faz-se salutar demarcar que a correlação entre a formação e as atribuições não parece ser necessariamente equivalente ao suposto grau de dificuldade da atividade a ser exercida. Observa-se, curiosamente, que o concurso A5 e os credenciamentos B1 e B3, que tratam de textos jurídicos e que possuem fé pública em todo território nacional (caso de A5), não exigem necessariamente formação de nível superior, embora o processo seletivo cuidadoso sem dúvida analise conhecimentos e histórico profissional que certifique a competência linguística dos candidatos.

Esse panorama converge com o debatido por Heilbron e Sapiro (2007) e Milton (2015), acerca do fato de que a formação acadêmica e a competência profissional não necessariamente se apresentam de maneira integrada, o que poderia ser considerado uma espécie de "falha estrutural". Seria necessário viabilizar um espaço institucional, de forma mais ampla, que agregasse conhecimento acadêmico e profissional. Caso contrário, o papel do agente tradutor se torna, em algumas instâncias, subvalorizado, reduzindo a amplitude de sua influência como propagador de relações de poder (Cf. GENTZLER; TYMOCZKO, 2002).

$\mathrm{Na}$ terceira etapa deste estudo, os conhecimentos necessários descritos nos editais selecionados são comparados no Quadro 4.

Quadro 4. Comparação de conhecimentos necessários para as seleções de concursos e credenciamento de tradutores

\begin{tabular}{|c|l|}
\hline Edital & \multicolumn{1}{|c|}{ Conhecimentos necessários } \\
\hline A1 & Língua Portuguesa e Língua Inglesa \\
\hline A2 & $\begin{array}{l}\text { Português, inglês, espanhol, conhecimentos gerais (Cultura, Direito Administrativo, } \\
\text { Direito Constitucional, Regimento Comum e Regimento dx [suprimido]) }\end{array}$ \\
\hline A3 & Português, Inglês e Informática \\
\hline A4 & Raciocínio lógico, Português e Inglês \\
\hline A5 & Português e Inglês
\end{tabular}




\begin{tabular}{|c|l|} 
A6 & $\begin{array}{l}\text { Português, Informática, Raciocínio Lógico, Plano Diretor dx [suprimido]; Conhecimentos } \\
\text { específicos: teorias da tradução, direitos autorais, normas de editoração dx [suprimido], } \\
\text { processo de produção gráfica e de edição; Tradução e Versão }\end{array}$ \\
\hline B1 & Conhecimento relativo à realização de tradução e versão \\
\hline B2 & $\begin{array}{l}\text { Conhecimentos na área de Tradução ou Letras (graduação); e na área Letras, } \\
\text { Linguística, Literatura ou Comunicação (pós-graduação). }\end{array}$ \\
\hline B3 & Conhecimento relativo à função de Tradutor Público e Intérprete Comercial \\
\hline
\end{tabular}

Fonte: Adaptado dos respectivos editais dos concursos

A análise contrastiva desses dados da terceira fase permite-nos perceber que houve certo progresso em considerar conhecimentos secundários como também importantes para a atividade do tradutor. Observa-se que apenas dois concursos (A1 e A5) priorizam uma abordagem mais estruturalista da atividade. As demais seleções, principalmente A2 e A6, esperam que o candidato tenha uma ambientação especializada mais complexa, que apoie a realização de suas atividades como tradutor. Nessa esteira, processos seletivos para atuação em âmbito institucional têm começado a reverberar a perspectiva integral defendida por Arrojo (1998) e Milton (2015).

\section{Considerações finais}

Em meio à reflexão sobre qual seria o verdadeiro vetor teórico da área de tradução, o formal ou o ideológico, depreende-se que a ideologia, materializada em relações de poder, delimita, sem sombra de dúvida, as fronteiras do que entendemos, e aceitamos como cultura, como social e até mesmo como individual. Nesse contexto, é inconteste que se deve focalizar o agente tradutor como elemento essencial para conceber teorias da tradução aplicadas à realidade prática (Cf. BLUME; PETERLE, 2013).

No entanto, ainda são bastante comuns indagações sobre o espaço da tradução em sociedade e em ambientes institucionais, se ela deve ser encarada apenas como uma atividade meio ou se realmente estaria imbricada com questões ideológicas. De forma mais direcionada, é necessário refletir se a maneira como a tradução é concebida em instituições governamentais é decorrente de perspectivas acadêmicas viciadas ou viceversa, e de que maneira seria possível transpor essas eventuais visões circunscritas a esses "conceitos definidos".

Na esteira de uma ambientação holística, pode-se afirmar que, embora haja um entendimento de que a ideologia desempenha um papel crucial na atividade do tradutor, ainda não são tão incomuns realidades institucionais motivadas por interesses econômicos. Nesse sentido, vícios acadêmicos, como demonstrado por Milton (2015) e 
Arrojo (1998), tendem a dificultar a devida progressão da área e sua integração adequada a espaços institucionais.

Embora a própria análise dos editais de concursos e de credenciamentos selecionados demonstre que um passo importante foi dado no sentido de oferecer espaço institucional para a tradução e, principalmente, para o tradutor, essa mudança de paradigma, como denomina Lambert (2013), ainda ocorre de forma bastante paulatina, sem necessariamente conferir-Ihes a devida expressividade em procedimentos estabelecidos dentro dessas instituições.

Atualmente, a própria delimitação da área de Estudos da Tradução tem sido revisitada e, nesse contexto, ocorre uma fragmentação crescente, em virtude justamente dessa flexibilização das fronteiras do mapa originalmente proposto por Holmes (2000 [1976]). Dentre as novas abordagens que complementam - ou mesmo impulsionam - os estudos da tradução (PYM, 1998), é possível citar a linguística computacional, campo que lida com ferramentas de corpus, essenciais para estudos de linguagem natural e contraste entre diferentes registros linguísticos ou gêneros textuais, por exemplo.

Ainda nessa esteira, podemos observar a influência de um modus operandi propriamente informatizado, que certamente está levando à institucionalização de uma virada tecnológica. As estruturas de poder, nesse contexto, passam a ser ainda mais potencializadoras de propagação ideológica, perspectiva na qual o agente tradutor certamente estará evidenciado mais contundentemente, em função do alcance de imagens e papéis desempenhados virtualmente, o que se tornou uma realidade ainda mais presente em situações de contingenciamento de pandemias, como no caso da COVID-19.

\section{Agradecimentos}

Este trabalho foi realizado em alinhamento com a pesquisa desenvolvida por mim no âmbito do Núcleo de Estudos Interdisciplinares em Ciências Aeroespaciais (NEICA), da Universidade da Força Aérea (UNIFA), grupo cadastrado no diretório do CNPq, particularmente na linha de pesquisa "Discurso, Práticas Profissionais e Tradução Institucional". Agradeço aos colegas e ao NEICA pela oportunidade de reflexão sobre o tema.

\section{REFERÊNCIAS}

ÁlVAREZ, R.; VIDAL, M. C.-Á. Translating: A Political Act. In: ÁLVAREZ, R.; VIDAL, M. C.-Á. (org.). Translation, Power, Subversion. Clevedon/Philadelphia: Multilingual Matters, 1996. p. 1-9. 
ARROJO, R. Os 'estudos da tradução' como área de pesquisa independente: di-lemas e ilusões de uma disciplina em (des)construção. D.E.L.T.A., São Paulo, v. 14, n. 2, p. 423-454, 1998.

BASSNETT, S. A origem e o desenvolvimento dos estudos da tradução. Tradução Maria Gil. In: BASSNETT, S. Translation. Londres/Nova York: Routledge, 2014. p. 16-36.

BLUME, R. F.; PETERLE, P. Tradução e relações de poder: algumas reflexões introdutórias. In: BLUME, R. F.; PETERLE, P. (org.). Tradução e relações de poder. Florianópolis: PGET/ UFSC, 2013. p. 7-19.

BRITTO, P. Desconstruir para quê? Cadernos de Tradução, Florianópolis, v. 2, n. 8, p. 41-50, 2001.

GENTZLER, E.; TYMOCZKO, M. Introduction. In: GENTZLER, E.; TYMOCZKO, M. (org.). Translation and Power. Amherst/Boston: University of Massachusetts Press, 2002. p. xixxviii.

HEILBRON, J.; SAPIRO, G. Outline for a Sociology of Translation. In: WOLF, M.; FUKARI, A. (org.). Constructing a Sociology of Translation. Nova York/Amsterdam: John Benjamins, 2007. p. 93-105.

HOLMES, J. The Name and Nature of Translation Studies. In: VENUTI, L. (org.). The Translation Studies Reader. Londres/Nova York: Routledge, 2000 [1976]. p. 172-185.

KANG, J.-H. Institutional Translation. In: BAKER, M.; SALDANHA, G. (org.). Routledge Encyclopedia of Translation Studies. 3. ed. Londres; Nova York: Routledge; Taylor \& Francis, 2020. p. 256-261.

KOSKINEN, K. Institutional translation. In: GAMBIER, Y.; DOORSLAER, L. van (org.). Handbook of Translation Studies. v. 2. Amsterdam; Filadélfia: John Benjamins Publishing Company, 2011. p. 54-60.

LAMBERT, J. Prelude: The institutionalization of the discipline. In: MILLÁN, C.; BARTRINA, F. (org.). The Routledge Handbook of Translation Studies. Londres/Nova York: Routledge, 2013. p. 7-28.

LAMBERT, J. Interview with José Lambert. Scientia Traductionis, Florianópolis, n. 7, p. 207234, 2010. 
MILTON, J. The Birth of Translation Studies on the Periphery: The Case of Brazil. In: SOUSA, G. H. P. de (org.). História da tradução: ensaios de teoria, crítica e tradução literária. Campinas: Pontes, 2015. p. 93-109.

MUNDAY, J. Main Issues of Translation Studies (Cap. 1, seções 1.2, 1.3 e 1.4). In: MUNDAY, J. Introducing Translation Studies - Theories and Applications. Londres/Nova York: Routledge, 2012 [2001]. p. 7-27.

PEIXOTO, R. A. J. R. P. Aeronautical Meteorology glossary: a discussion on term definition in the ANACpedia termbase. The Especialist, São Paulo, v. 42, n. 1, p. 1-24, 2020.

PYM, A. History. In: PYM, A. Method in Translation History. Manchester: St. Jerome, 1998. p. 1-19.

SCHLEIERMACHER, F. Hermeneutik und Kritik. Frankfurt: Suhrkamp, 1993.

SHUTTLEWORTH, M.; COWIE, M. Translation Studies. In: SHUTTLEWORTH, M.; COWIE, M. Dictionary of Translation Studies. Manchester: St. Jerome, 1997. p. 183-184.

SNELL-HORNBY, M. The pragmatic turn in linguistics. Translation Studies - The Emergence of a discipline. In: SNELL-HORNBY, M. The Turns of Translation Studies: new paradigms points? Amsterdam/Philadelphia: John Benjamins, 2006. p. 1-46.

VASCONCELLOS, M. L. Os Estudos da Tradução no Brasil nos séculos XX e XXI: ComUNIDADE na diversidade dos Estudos da Tradução? In: GUERINI, A.; TORRES, M.-H. C.; COSTA, W. C. (org.). Os Estudos da Tradução nos séculos XX e XXI. Florianópolis: PGET/ UFSC, 2013. p. 33-50. 